\title{
The experimental investigation of using thermography inspection for dry turning process diagnosis
}

\author{
JUSTYNA MOLENDA \\ Marine Maintenance Department \\ Faculty of Marine Engineering \\ Gdynia Maritime University \\ 81-225 Gdynia, 81-87 Morska St. \\ POLAND
}

\begin{abstract}
Increasing the productivity and the quality of the machined parts are the main challenges of metalbased industry. There has been increased interest in monitoring all aspects of the machining process. When cutting metals and alloys most of the energy required to form the chips is converted into heat. Therefore, the temperatures generated in the cutting zone are an important factor to take into consideration. This factor is of a major importance to the performance of the cutting tool and quality of the work piece. Temperature at the cutting point of the tool is then a crucial parameter for controlling the course of turning process.

Temperature monitoring by used of thermovision cameras provides a lot of information about thermal behavior of machines, tools and processes since they monitor large areas during normal operation. The article presents the research results referring to the observation of changes of cutting zone temperature with cutting parameters during turning of AW-7020.
\end{abstract}

Key-Words: - thermovision, infrared inspections, 7020 aluminium alloy, turning process

Received: May 13, 2020. Revised: September 1, 2020. Accepted: September 13, 2020. Published: September 23, 2020.

\section{Introduction}

Temperature is one of the major diagnostic parameters. It can be a valuable source of diagnostic information about technical condition of elements, whole machines and devices and course of processes and phenomena.

In turning, approximately all of the work (energy) done by a cutting tool in removing metal is converted into heat which is dissipated into the chip, tool and workpiece material. The chip, tool and workpiece help to remove this heat from the cutting zones (Fig. $1)$.

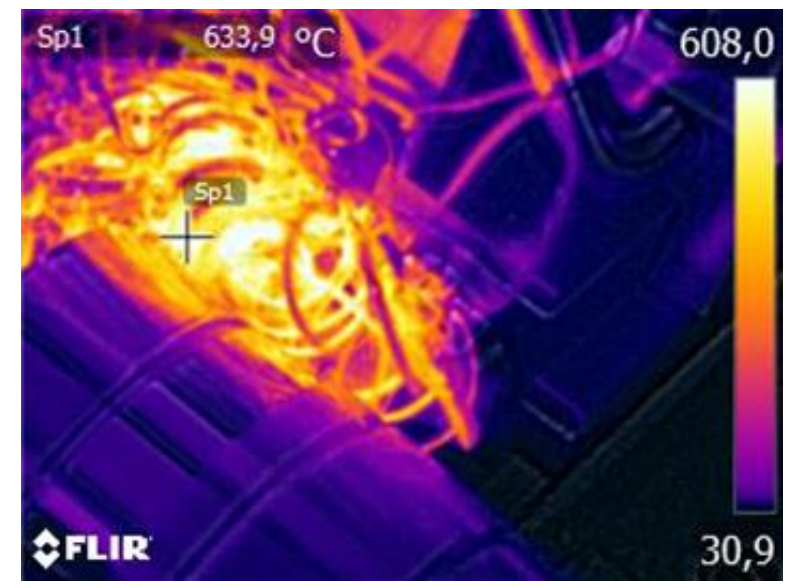

Fig. 1. Temperature distribution in cutting zone during turning of steel

Studies have shown that maximum amount of heat is carried away by the flowing chip. From 10 to $20 \%$ of the total heat goes into the tool and some heat is absorbed in the workpiece $[2,11,13]$.

Temperature at the cutting point of the tool is a crucial parameter in the control of the machining process. Interfacial temperatures in turning play a major role in tool wear, and can also result in modifications to the properties of the workpiece and tool materials. It is well known that the temperature of the cutting tool, the chip and the workpiece can be significantly increased during machining and that it can reach for steel levels typically of $750{ }^{\circ} \mathrm{C}$. 


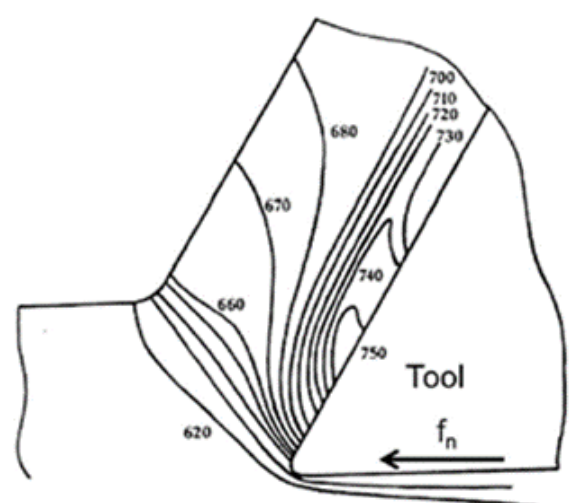

Fig. 2. Typical temperatures near the tool-chip interface (in ${ }^{\circ} \mathrm{C}$ ) [3]

Using coolants and lubricants during machining processes increases costs, has negative environmental impact and causes workers' health hazards. Thus, there is a general move towards dry machining $[4,7]$. Considering above it is increasingly important to understand how machining temperatures are affected by the process parameters: cutting speed, feed rate, tool geometry, and by other factors such as tool wear and the characteristics of workpiece material (e.g., thermal diffusivity and hardness). An example of a typical temperature distribution in the cutting zone is shown in Fig. 2 , where $f_{n}$ is the feed direction $[3,9,10]$.

For the improvement of cutting performance, the knowledge of temperature at the tool-chip interface with good accuracy is essential. Since that at the interface there is a moving contact between the tool and chip, not every experimental technique can be used to measure the interface temperature. The main techniques used in temperature measurement during machining engaged thermocouples. Thermocouples have always been a popular transducers used in temperature measurements. They are very rugged and inexpensive and can operate over a wide range of temperature values. It is easy to apply those techniques, but measure only the mean temperature over the entire contact area. High local or flash temperatures which may occur for a short period of time cannot be observed $[1,2,8,9]$.

In this work infrared technology is proposed. Thermography is not a new phenomenon - it has been utilized successfully in industrial and research settings for decades - but new innovations have reduced costs, increased reliability, and resulted in noncontact infrared sensors offering smaller units of measurement.

The advantages offered by noncontact temperature measurement are:

1. it is fast (in the ms range) - time is saved, allowing for more measurements and accumulation of data (determination of temperature field),
2. it facilitates measurement of moving targets (conveyor processes),

3. measurements can be taken of hazardous or physically inaccessible objects (high-voltage parts, great measurement distance),

4. measurements of high temperatures (greater than $1300^{\circ} \mathrm{C}$ ) present no problems. In similar cases, contact thermometers cannot be used, or have a limited life,

5. there is no interference - no energy is lost from the target. For example, in the case of a poor heat conductor such as plastic or wood, measurements are extremely accurate with no distortion of measured values, as compared to measurements with contact thermometers,

6. there is no risk of contamination and no mechanical effect on the surface of the object; thus wear-free. Lacquered surfaces, for example, are not scratched and soft surfaces can also be measured.

All of these factors have led infrared technology to become an area of interest for new kinds of applications and users. Today, the IR thermography is applied in numerous human activities, such as: astronomy (telescope), firefighting operations, military and police surveillance, target detection and acquisition, law enforcement and anti-terrorism, predictive engineering maintenance of mechanical and electrical equipment, process monitoring, condition monitoring and surveillance, energy auditing of insulation, roof inspection, masonry wall structural analysis, moisture detection in walls and roofs, medical testing for diagnosis, non-destructive testing, quality control in production environments, research and development of new products, effluent pollution detection, locating of unmarked graves, aerial archaeology, search and rescue operations, etc. $[9,12]$.

\section{Research methodology}

Experiments were carried out on a conventional lathe CU500MRD/1000 type (Fig. 3) without using any coolant. Commercially available turning insert CCGT09T302-DL type by Duracarb was used. 


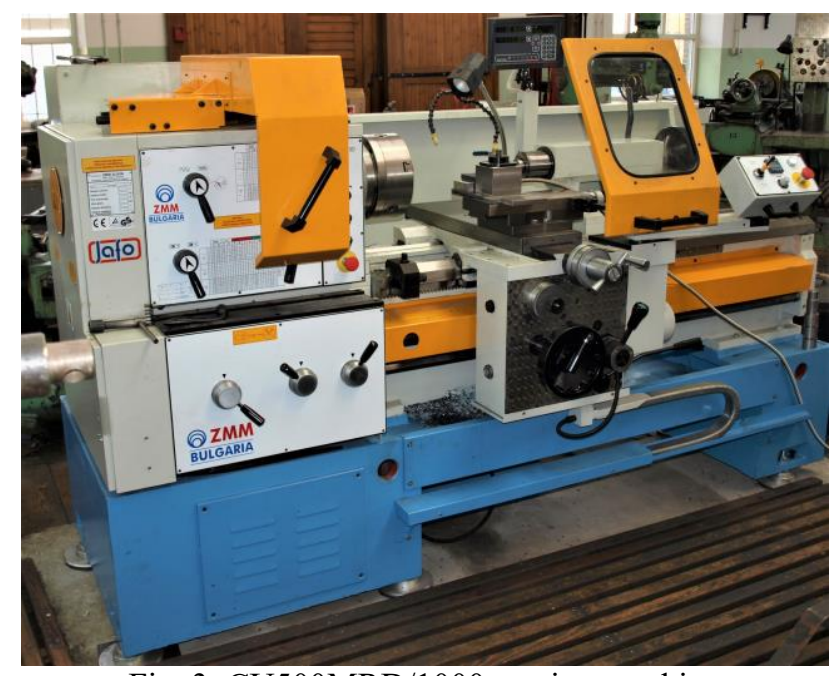

Fig. 3. CU500MRD/1000 turning machine

The machining was performed using workpiece of AW-7020 aluminum alloy. Aluminium alloys (except for some grades) are well machinable, however their machinability is different from other metals which requires different machining conditions. This is due to the properties of aluminium alloys such as: high coefficient of linear expansion (for steel this factor is twice lower), high thermal conductivity [5]. Workpiece diameter was equal $55 \mathrm{~mm}$. As can be seen in Fig. 4 the element was prepared before. Its length was divided to 6 short sections, each for one set of cutting parameters.

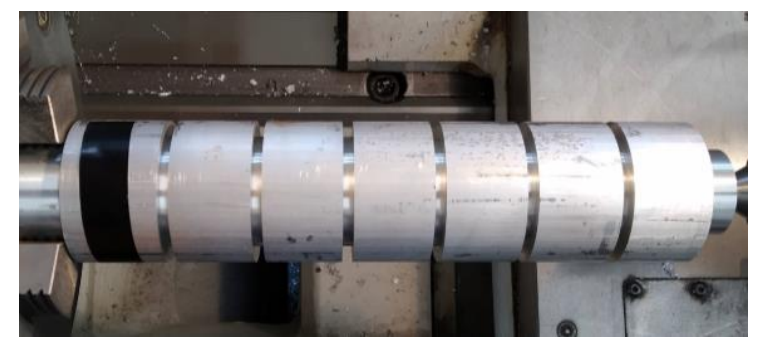

Fig. 4. AW-7020 workpiece

Temperature was measured by infrared camera E95 produced by FLIR ${ }^{\circledR}$ Systems, Inc. (Fig. 5).

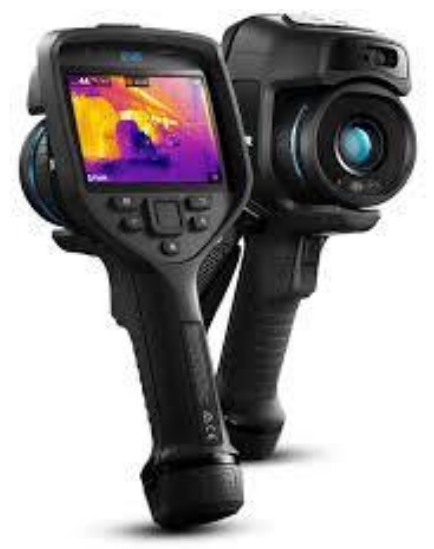

Fig. 5. E95 thermographic camera [4]

The camera serves for contact-less, remote temperature measurement and visualization of its distribution. As a result of a measurement it is obtained a data set that is presented in a form of a colour map: a thermogram. The thermogram consists of 161472 measuring points (464 points in 348 lines). The camera views and measures highest temperatures from -20 to $+1800^{\circ} \mathrm{C}$ with thermal sensivity $\pm 0,03{ }^{\circ} \mathrm{C}$. The camera employs a gun grip design with multi touch monitor similar to that of a smartphone or tablet, which enables one-hand operation. The image capture support functions of a 5-megapixel digital camera.

All methods of non-contact temperature measurement employed by the radiation thermometers are indirect methods. Output temperature is determined on the basis of the power of thermal radiation emitted by the tested object and measured in one or more spectral bands using different mathematical models. Parameters of the model are: emissivity of tested object, atmospheric temperature, relative humidity, object distance. All those parameters values can be changed by the operator in time of testing or after during analyzing the results. They should be estimated properly. Incorrect values will cause measurement error. The most influencing parameters are emissivity and reflected temperature $[5,12]$.

Those two were obtained at the very beginning. Emissivity $\varepsilon$ measures the ratio of thermal radiation, which is generated by a gray and a black body of equal temperature. The maximum emissivity for the black body is 1 .

a)

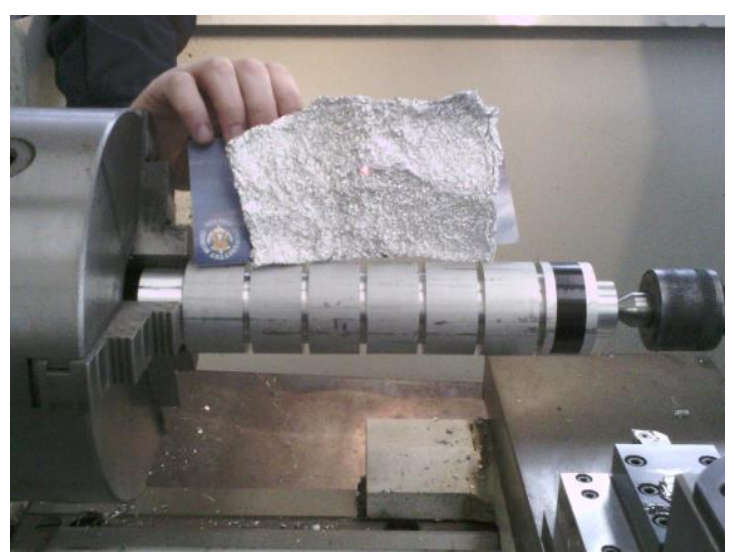

b) 


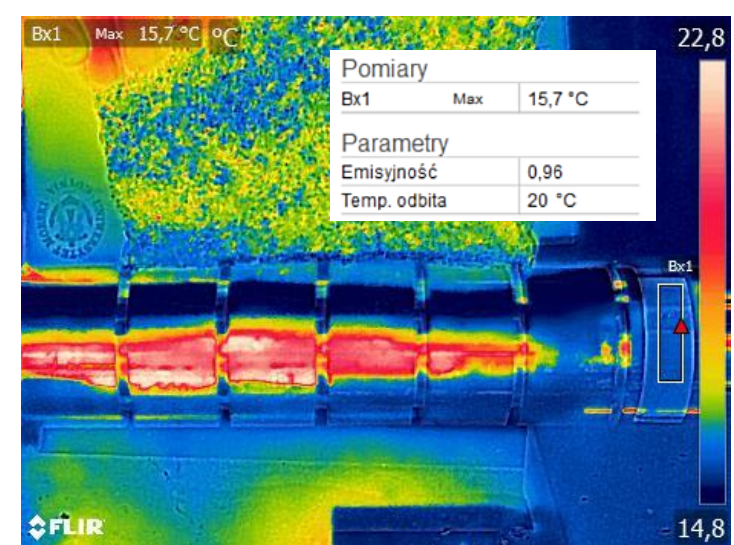

c)

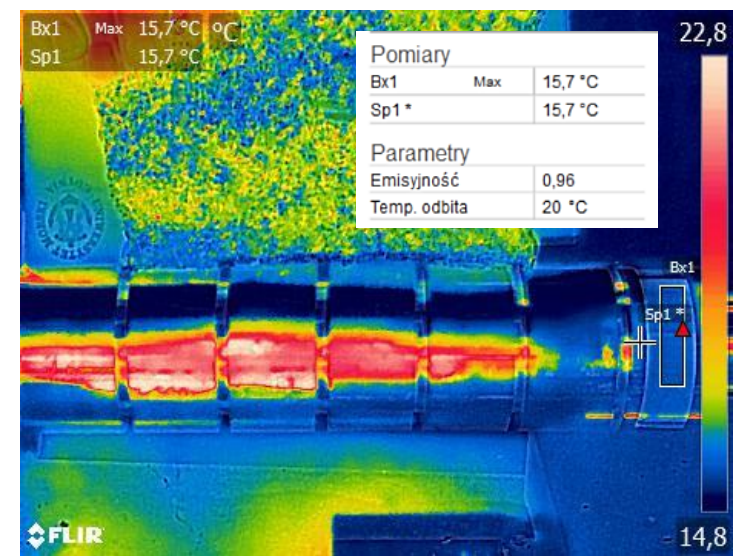

Fig. 6. Determining measurements parameters: emissivity before turning

There are different ways to determine emissivity. In this work method with applying reference emissivity was used. To the shaft a black insulating tape was applied (Fig. 6a). Its emissivity equal 0.96 was entered to the infrared camera and then temperature of band (rectangular area $\mathrm{Bx} 1$ ) was measured (Fig. 6b). Subsequently, the temperature next to the band was measured (Sp1), whereby the emissivity must simultaneously be adjusted until the same temperature measurement of the band is displayed.

Determined emissivity of the shaft was 0.97 which is consistent with emissivity tables (for oxide aluminum $\varepsilon=0.97$ ).

In the next step, with use of the same method, shaft emissivity after turning was determined (Fig. 7). Obtained value was $\varepsilon=0,16$.
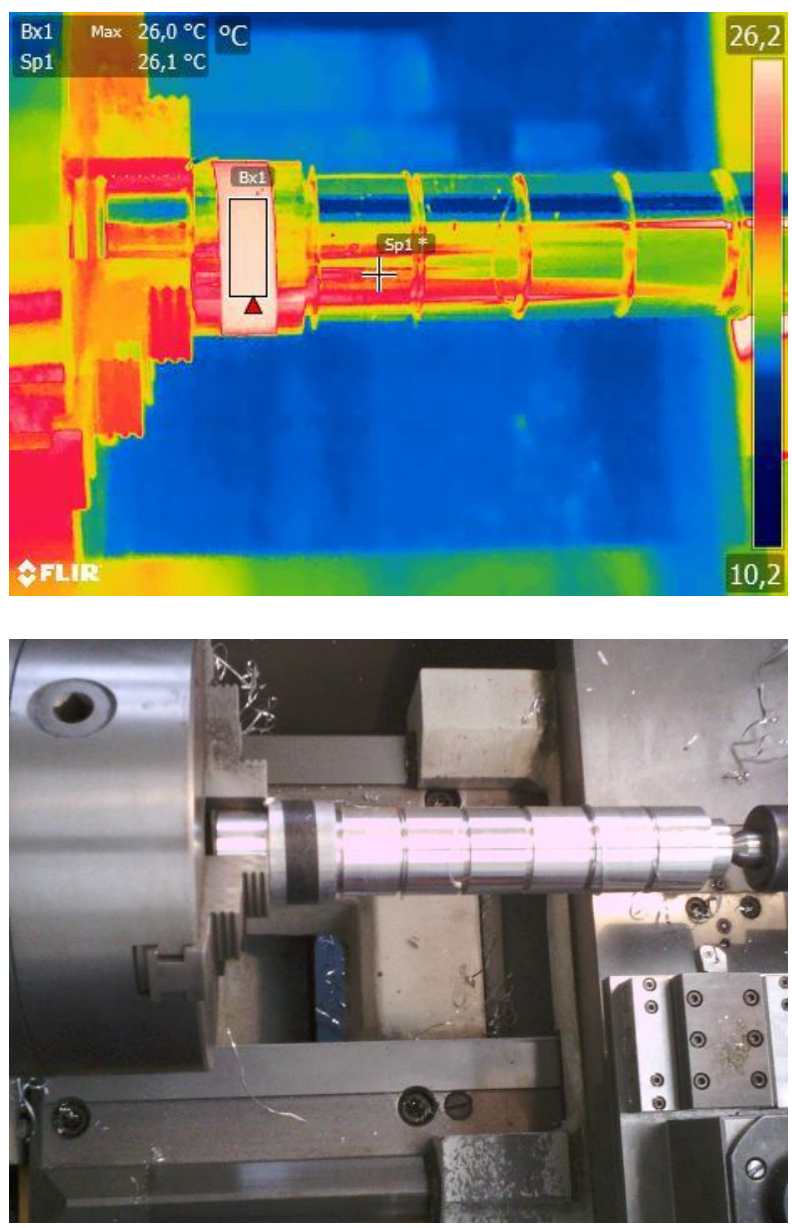

Fig. 7. Determining measurements parameters: emissivity after turning

The reflected temperature which is the result of reflected radiation from the surroundings was analyzed then. In Fig. 6a can be seen a special mirror. It was prepared with use of food grade aluminum foil with aim to gather reflections from many different angles. Average temperature from area $\mathrm{B} \times 2$ is $16,5{ }^{\circ} \mathrm{C}$ and this value was used as reflected temperature in further measurements.

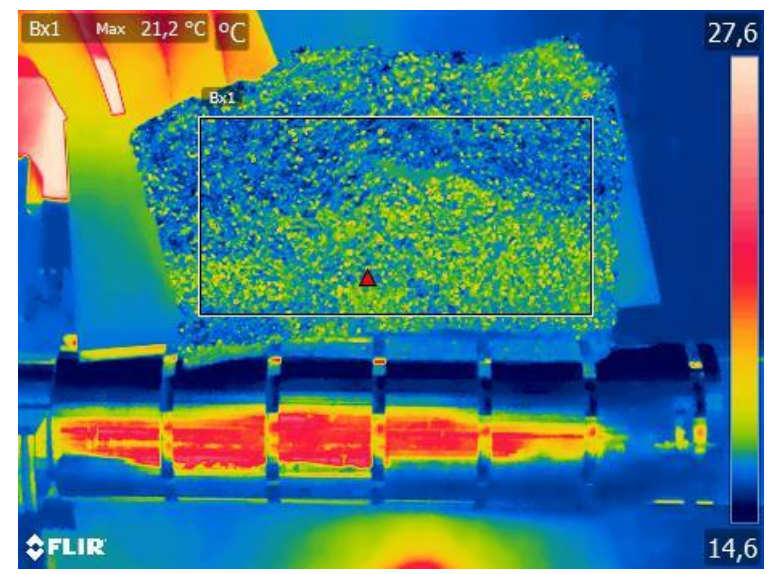




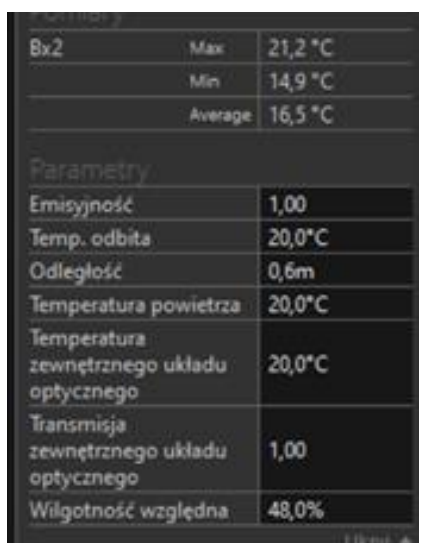

Fig. 8. Determining measurements parameters: reflected temperature

The research was carried out with different values of cutting parameters: cutting speed (Vc), feed (f) and depth of cut (ap). All used values are presented in Table 1.

Table 1. Cutting parameters for AW-7020 turning

\begin{tabular}{|c|c|c|c|}
\hline \multirow{2}{*}{$\begin{array}{c}\text { Test } \\
\text { no. }\end{array}$} & \multicolumn{3}{|c|}{ cutting parameters } \\
\cline { 2 - 2 } & $\mathrm{Vc}[\mathrm{m} / \mathrm{mm}]$ & $\begin{array}{c}\mathrm{f} \\
{[\mathrm{mm} / \mathrm{rev}]}\end{array}$ & $\begin{array}{c}\text { ap } \\
{[\mathrm{mm}]}\end{array}$ \\
\hline 1 & 172.7 & \multirow{2}{*}{0.1} & 3.0 \\
\hline 2 & 172.7 & & 2.0 \\
\hline 3 & 172.7 & & 1.0 \\
\hline 4 & 172.7 & \multirow{2}{*}{0.3} & 1.0 \\
\hline 5 & 172.7 & & 2.0 \\
\hline 6 & 172.7 & & 3.0 \\
\hline 7 & 310.9 & \multirow{2}{*}{0.3} & 3.0 \\
\hline 8 & 310.9 & & 2.0 \\
\hline 9 & 310.9 & & 1.0 \\
\hline 10 & 310.9 & \multirow{2}{*}{0.1} & 3.0 \\
\hline 11 & 310.9 & & 2.0 \\
\hline 12 & 310.9 & & 1.0 \\
\hline
\end{tabular}

\section{Research Results}

Experiments were conducted during turning in described conditions with aim to measure temperatures at the point of tool and workpiece contact (Fig. 9).

a)

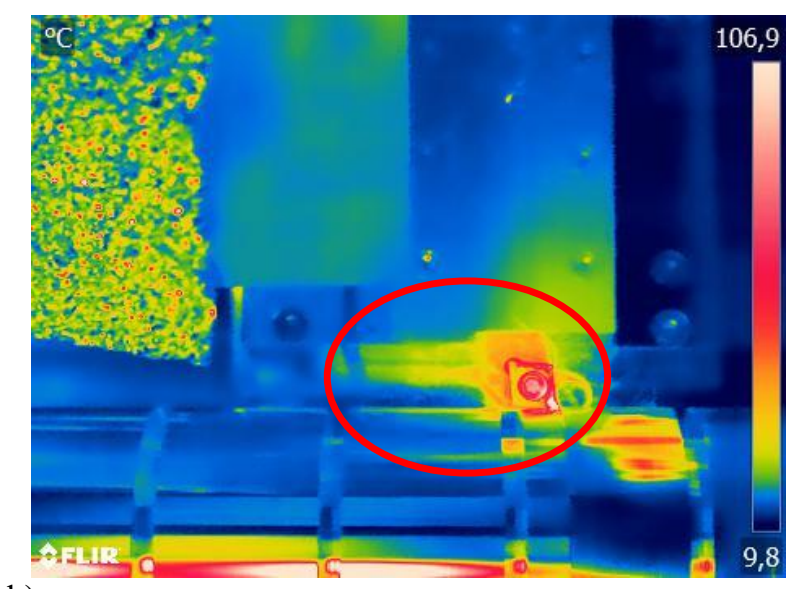

b)

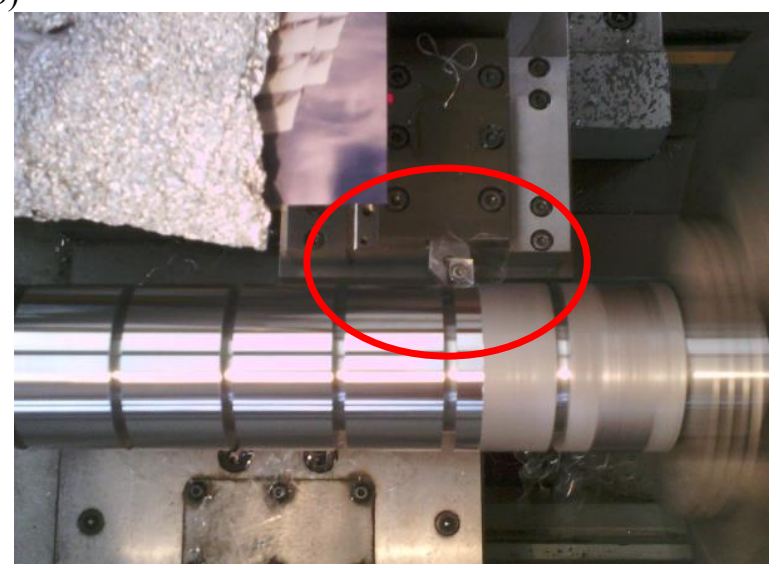

Fig. 9. Cutting zone: a) thermal view, b) visible picture

Examples of obtained thermal images are presented in Fig. $10-12$.

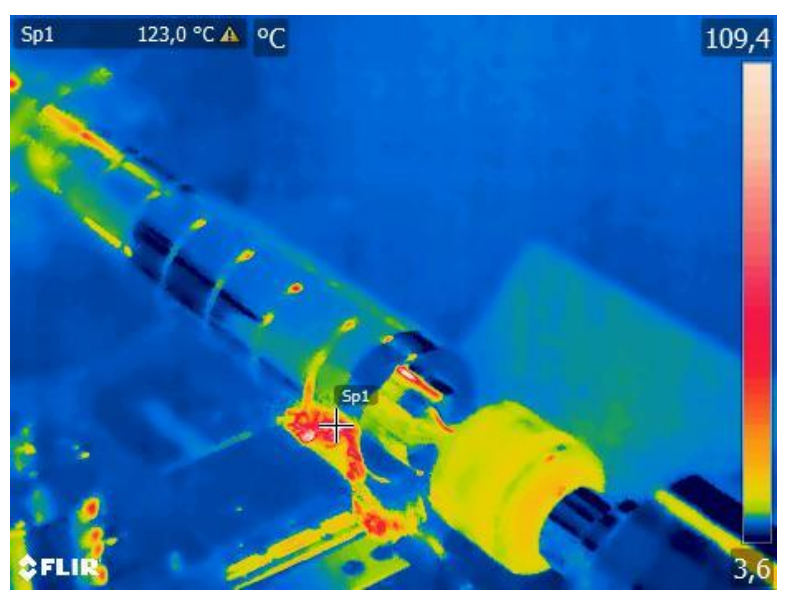

Fig. 10. Thermogram obtained during test no. 1 


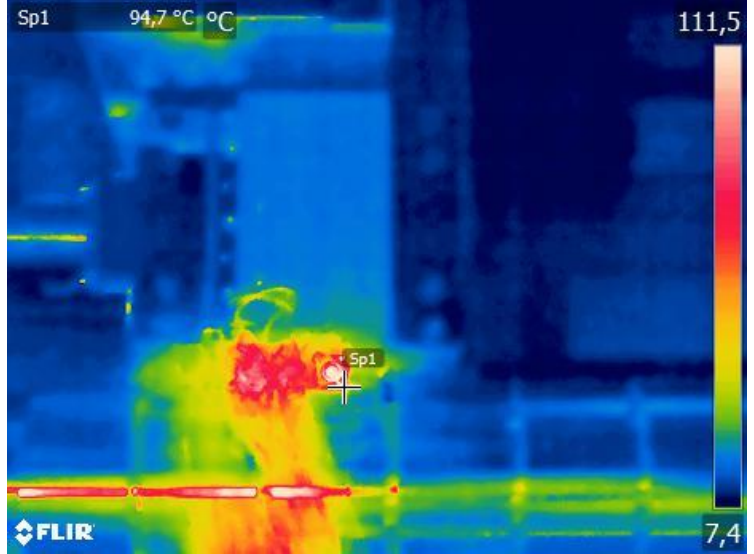

Fig. 11. Thermogram obtained during test no. 3

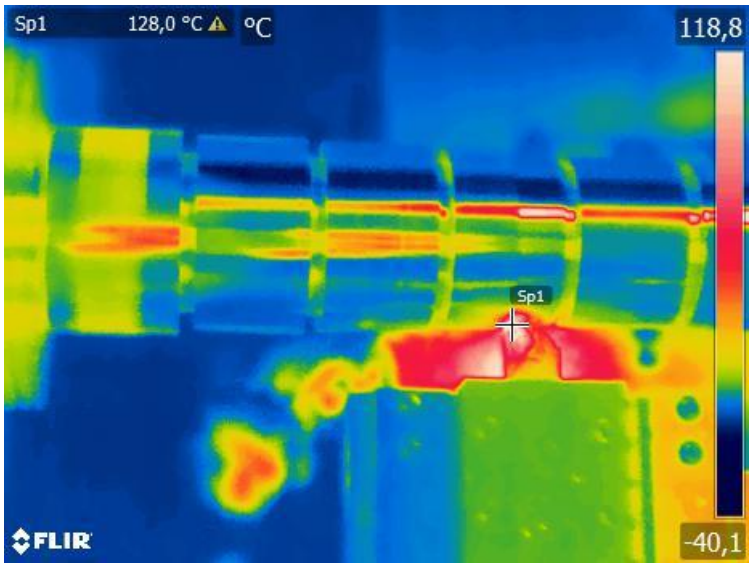

Fig. 12. Thermogram obtained during test no. 10

All measured temperature values are presented in Table 2.

Table 2. Cutting parameters for AW-7020 turning

\begin{tabular}{|c|c|c|c|c|}
\hline \multirow[b]{2}{*}{ No. } & \multicolumn{2}{|c|}{ cutting parameters } & \multicolumn{2}{|c|}{ results } \\
\hline & $\begin{array}{c}\mathrm{Vc} \\
{[\mathrm{m} / \mathrm{mm}]}\end{array}$ & $\begin{array}{c}\mathrm{f} \\
{[\mathrm{mm} / \mathrm{rev}]}\end{array}$ & $\begin{array}{c}\text { ap } \\
{[\mathrm{mm}]}\end{array}$ & $\begin{array}{c}\mathrm{T} \\
{\left[{ }^{\circ} \mathrm{C}\right]}\end{array}$ \\
\hline 1 & 172.7 & \multirow{3}{*}{0.1} & 3.0 & 123.0 \\
\hline 2 & 172.7 & & 2.0 & 116.6 \\
\hline 3 & 172.7 & & 1.0 & 94.7 \\
\hline 4 & 172.7 & \multirow{3}{*}{0.3} & 1.0 & 112.6 \\
\hline 5 & 172.7 & & 2.0 & 125.6 \\
\hline 6 & 172.7 & & 3.0 & 130.3 \\
\hline 7 & 310.9 & \multirow{3}{*}{0.3} & 3.0 & 131.4 \\
\hline 8 & 310.9 & & 2.0 & 119.2 \\
\hline 9 & 310.9 & & 1.0 & 124,4 \\
\hline 10 & 310.9 & \multirow{3}{*}{0.1} & 3.0 & 128.0 \\
\hline 11 & 310.9 & & 2.0 & 112.7 \\
\hline 12 & 310.9 & & 1.0 & 108.7 \\
\hline
\end{tabular}

After analyse of presented results it seems the influence of cutting parameters on temperature is negligible. However, there can be seen some trends. Small increase of temperature value is connected with depth of cut. The bigger depth of cut, the higher temperature. The same correlation is present in case of feed rate. It seems that cutting speed has any influence on analysed temperature.

As it was mentioned, aluminium alloys belong to group of materials that cause difficulties during machining. During experiments presented here, the biggest problems were snarled chips, which were present in most tests. That type of chips is dangerous for operators and for devices like camera. In this research lot of chips wrapped over workpiece and tool and make observation very hard. The chips have also big advantages - they took from cutting zone a lot of generated heat what can be seen in Fig. 13.

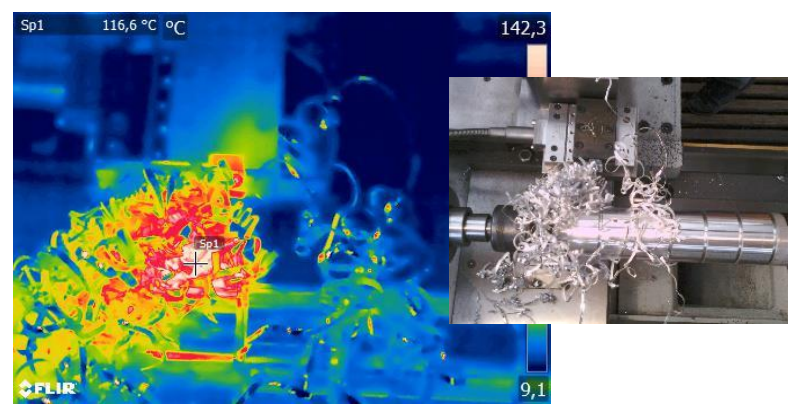

Fig. 13. Thermal and visible image obtained during test no. 2
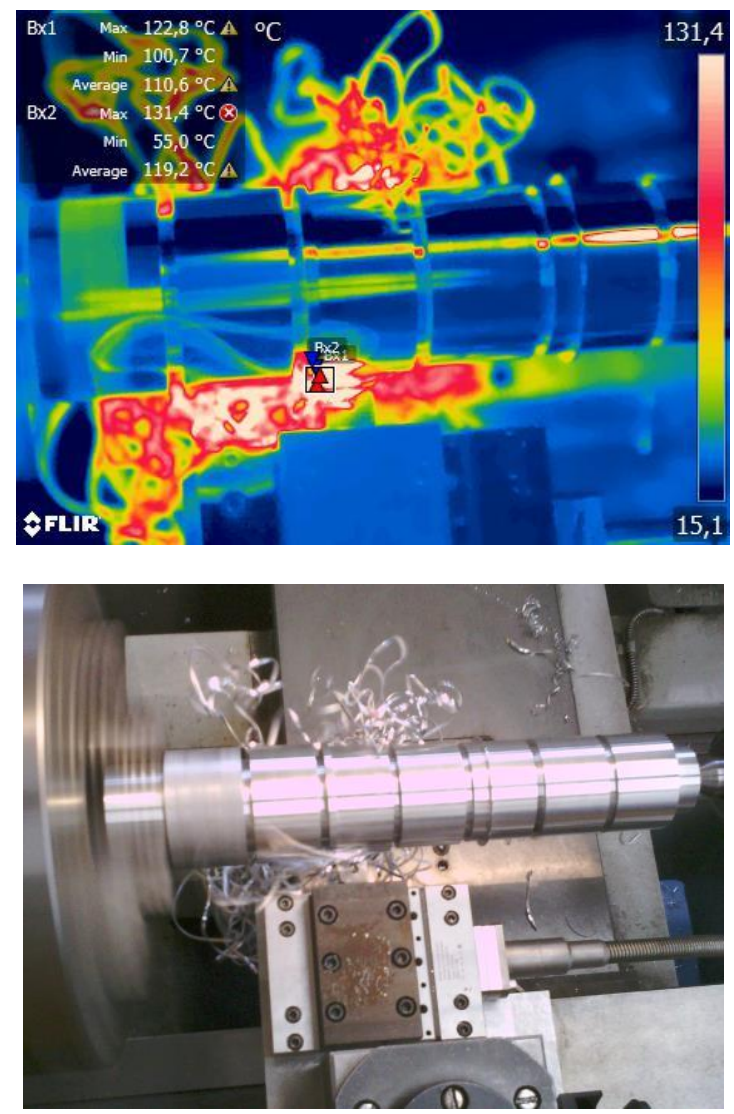

Fig. 14. Thermal and visible image obtained during test no. 8 

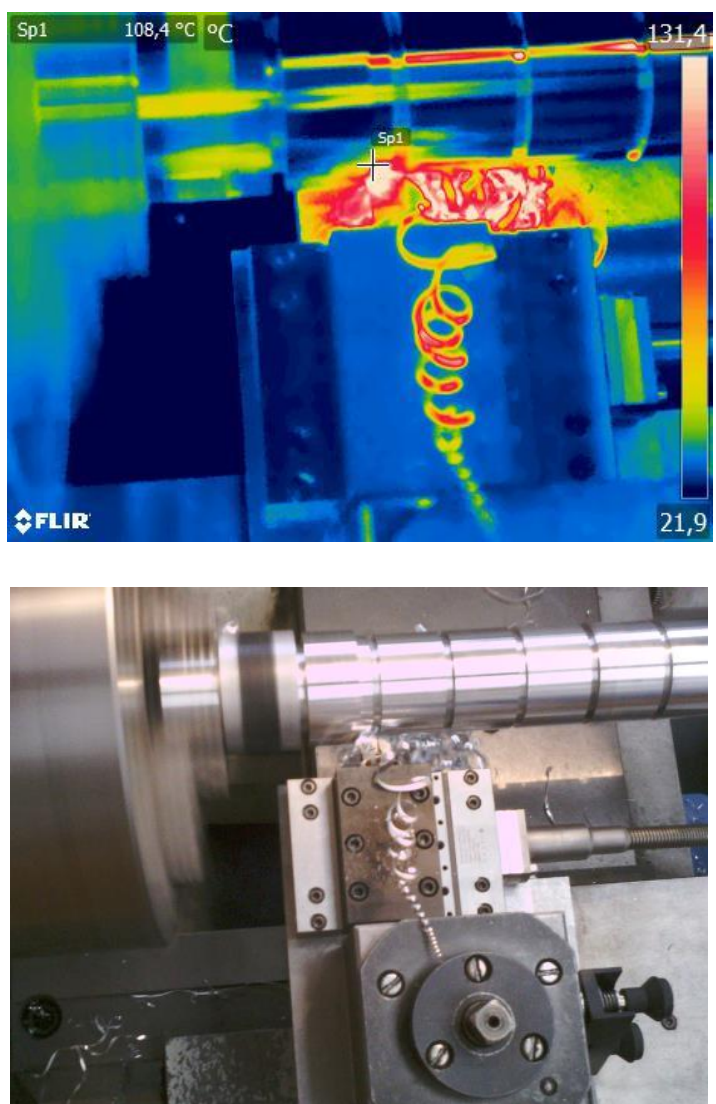

Fig. 15. Thermal and visible image obtained during test no. 12

\section{Conclusion}

Nowadays lot of scientific work inspired by industry companies was done with the aim to avoid or minimize the use of cutting fluids in machining operations. The reasons were ecological and human health problems caused by the cutting fluid and of course financial. Approximately $15-25 \%$ of total cost of production is spent for coolant. The most logical solution which can be taken to eliminate all of the problems associated with the use of cooling lubricant is dry machining. When cutting metals and alloys most of the energy required to form the chips is converted into heat. During dry machining the heat cannot be taken away by coolant. Therefore, the temperatures generated in the cutting zone are an important factor to take into consideration. In this work the influence of turning parameters on temperature in cutting zone was investigated. Obtained results shows that for aluminum alloy the maximum temperatures were safely low, not higher than $132{ }^{\circ} \mathrm{C}$. Moreover, there can't be seen the significant impact of turning parameters on temperature in cutting zone.

During experiments infrared thermography for measuring temperature was proposed. This technique has a lot of advantages, the main is that it is non- contact technique and therefore there is no disturbance of the temperature field but requires well prepared operator who avoids measure errors and guarantee appropriate results. Using alternative method for temperature measuring, like thermocouples, is difficult in case of moving elements and not enabling measuring the temperature in contact point between workpiece and the tool.

\section{References:}

[1] L. B. Abhang, M. Hameedullah, Chip-Tool Interface Temperature Prediction Model for Turning Process, International Journal of Engineering Science and Technology, Vol. 2, No. 4, 2010, pp. 382-393.

[2] L. B. Abhang, M. Hameedullah, The Measurement of Chip-Tool Interface Temperature in the Turning of Steel, International Journal of Computer Communication and Information System, Vol. 2, No. 1, 2010, pp.1-5.

[3] N. Ånmark, A. Karasev, G. Jönsson, The Effect of Different Non-Metallic Inclusions on the Machinability of Steels, Materials, Vol. 8, 2015, pp. 751-783.

[4] Y. R. Ginting, B. Boswell, W. Biswas, N. Islam, Advancing Environmentally Conscious Machining, Procedia CIRP, Vol. 26, 2015, pp. 391-396.

[5] Information on www.flir.eu.

[6] J. Kuczmaszewski, K. Zaleski, Machining of Aluminium and Magnesium Alloys, Monographs, Lublin University of Technology, Poland, 2015.

[7] J. Kundrák, G. Varga, I. Deszpoth, Analysis of Extent of Environment Load in Alternative Manufacturing Procedure, WSEAS Transactions on Environment and Development, Vol. 14, 2018, pp. 313-320.

[8] W. Labuda, The Influence of Treatments Conditions on Cutting Forces and Temperature During Finish Turning of Stainless Steel by CCET09T302R-MF Insert. 27th International Conference on Metallurgy and Materials, TANGER, Proceedings Paper, 2018, pp. 1163 1168.

[9] J. Molenda, A. Charchalis, The Influence of the Temperature of the Elements of the Lapping Machine Executory System on the Results of the Lapping Process. Solid State Phenomena, 2015, Vols. 220-221, pp. 871-874. 
[10] J. Molenda, The Experimental Investigation of Surface Roughness After Dry Turning of Steel S235, Journal of KONES Powertrain and Transport, Vol. 26, No. 4, 2019, pp. 179-184.

[11]J. Molenda, A. Charchalis, Preliminary Research of Possibility of Using Thermovision for Diagnosis and Predictive Maintenance of Marine Engines, Journal of KONBiN, Vol. 49, No. 3, 2019, pp. 49-56.

[12] Principles of noncontact temperature measurement, Fluke Process Instrument.

[13] S. J. Yaseen, Theoretical Study of Temperature Distribution and Heat Flux Variation in Turning Process, Al-Qadisiya Journal for Engineering Sciences, Vol. 5, No. 3, 2012, pp. 299-313.

\section{Creative Commons Attribution License 4.0 (Attribution 4.0 International, CC BY 4.0)}

This article is published under the terms of the Creative Commons Attribution License 4.0

https://creativecommons.org/licenses/by/4.0/deed.en_US 